\title{
Post-Marketing Safety Experience of Vedolizumab in Patients Receiving Concomitant Treatment with Other Biologics
}

Russell D Cohen', Fatima Bhayat', Aimee Blake ${ }^{2}$, Simon Travis ${ }^{3}$

'Department of Medicine, Inflammatory Bowel Disease Center, University of Chicago Medicine, Chicago, LL, USA; TTakeda Pharmaceutical International Co., Cambridge, MA, USA;
TTranslational Gastroenterology Unit, NIHR Oxiord Biomedical Research Centre, Oxford University Hospitials NHS Foundation Trust, John Radclifie Hospitital, Oxford, UK

\section{Background}

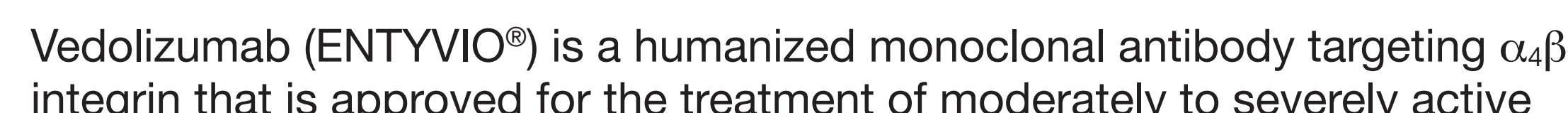
Crohn's disease (CD) and ulcerative colitis (UC) in adults. ${ }^{1,2}$ everely active
Concomitant use of other biologics with vedolizumab is not recommended in the vedolizumab prescribing information' and has not been evaluated in clinical trials, meaning that safety data are limited on patients receiving We compared 4 years of post-marketing safety data collated by Takeda
this Pharmaceutical Company Ltd (Takeda) on patients receiving vedolizumab and
concomitant biologics with patients receiving vedolizumab and non-biologic
concomitant therapy.

Methods

\section{All post-marketing adverse event (AE) reports received by the licence holder,
Takeda, since the date of first approval of vedolizumab (20 May 2014) are held in the Vedolizumab \\ spontaneous reports \\ reports extracted from the literature. \\ AE reports received between first approval of vedolizumab and 19 May 2018 that contained data on concomitant medication use were identified for review, using Patients reporting concomitant medication use were stratified into two grous: patients receiving vedolizumab with concomitant biologics (and additional non-biologic treatments in some cases, including corticosteroids or other non-biologic immunomodulators \\ paltents receiving vedolizumab with concomitant non-biologic therapy Data on patients who were not reported to have received any form of conct

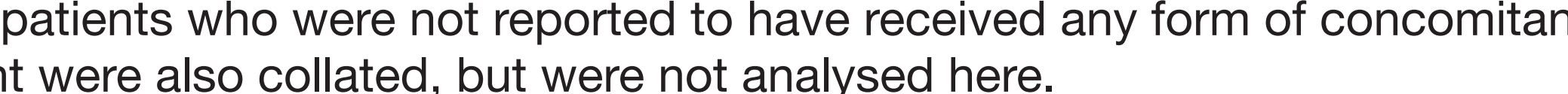 The estimated global vedolizumab exposure in the post-marketing setting was calculated based on the number of vials shipped worldwide, assuming 8-week}

Results

Overview of patient characteristics and total adverse events In the context of an estimated 208050 patient-years of vedolizumab exposure in
the post-marketing setting, 32752 patients reported AEs, with 80218 AEs reporte

There were 1112 patients ( $3 \%$ of all AE-reporting patients; 460 with $C D, 543$ with bowel disease, off-label use or an unreported indication) receiving vedolizum

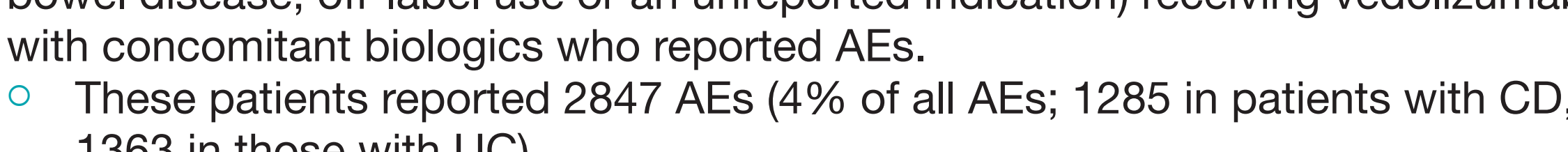

There were 20201 patients (62\% of all AE-reporting patients; 8861 with CD, These patients reported a total of 54855 AEs $68 \%$
Tos. The remaining 11439 patients reporting AEs (35\% of all AE-reporting patients; receiving any form of concomitant treatment (data for these patients were no analysed here). These patients reported a total of 22516 AEs ( $28 \%$ of all AEs; $46 \%$ in patients

Proportions of patients in each age group and sex were similar in those with Most patients were aged $18-64$ years (87\% of patients receiving concomitant biologics, $78 \%$ of those receiving concomitant non-biologic therapy), while a total of $53 \%$ and $56 \%$ of patients were female, respectively (Table 1). Of the patients receiving concomitant biologics,

- Similar proportions of patients receiving concomitant treatment both with and without biologics reported use of concomitant corticosteroids $444 \%$ vs $49 \%$, respectively) and/or concomitant non-biologic immunomodulator use (30\% vs $24 \%$, respectively.

Adverse events in patients receiving concomitant biologics and concomitant non-biologic therapy

The proportions of AEs reported in each category of AE were similar for patients medications that did not include other biologics. In patients receiving concomitant biologics, 1003 patients with CD or UC reported a total of $2648 \mathrm{AEs}$ : there were 202 infections ( $8 \%$ of AEs reported in this patient group), $43(21 \%)$ of which were serious (Figure 1 )

there were 7 post-operative complications ( $<1 \%$ of AEs), 16 infusion-site there were $7 \mathrm{AEs}$ reported $(<1 \%$ of $\mathrm{AEs}$ ) that resulted in a fatal outcome in 5 patients $(4 \mathrm{CD}, 1 \mathrm{UC}$; Figure 1).

In patients receiving concomitant non-biologic therapy, 18974 patients with $\mathrm{CD}$

There were

Also reported were 186 post-operative complications ( $<1 \%$ of AEs),

453 infusion-site reactions ( $1 \%), 176$ malignancies $(<1 \%)$ and 140 fatal AEs $(<1 \%$ of $\mathrm{AES} ; 80 \mathrm{CD}, 60 \mathrm{UC}$; Figure 1$)$.
The most frequently reported serious infections in patients with concomitant The most frequently reported serious infections in patients with concomitan
biologics were intestinal abscess, anal abscess and pneumonia (two events each [9\% of serious infections for indication]) in $\mathrm{CD}$ and Clostridium difficile infection /colitis (three events [14\%]], pneumonia and cytomegaloviral infection/
colitis (two events each [10\%]) in UC.
Figure 1. The proportions of AEs in each AE category reported in patients receiving vedolizumab with concomitant biologics and with concomitant non-biologic therapy a) Patients with Crohn's disease

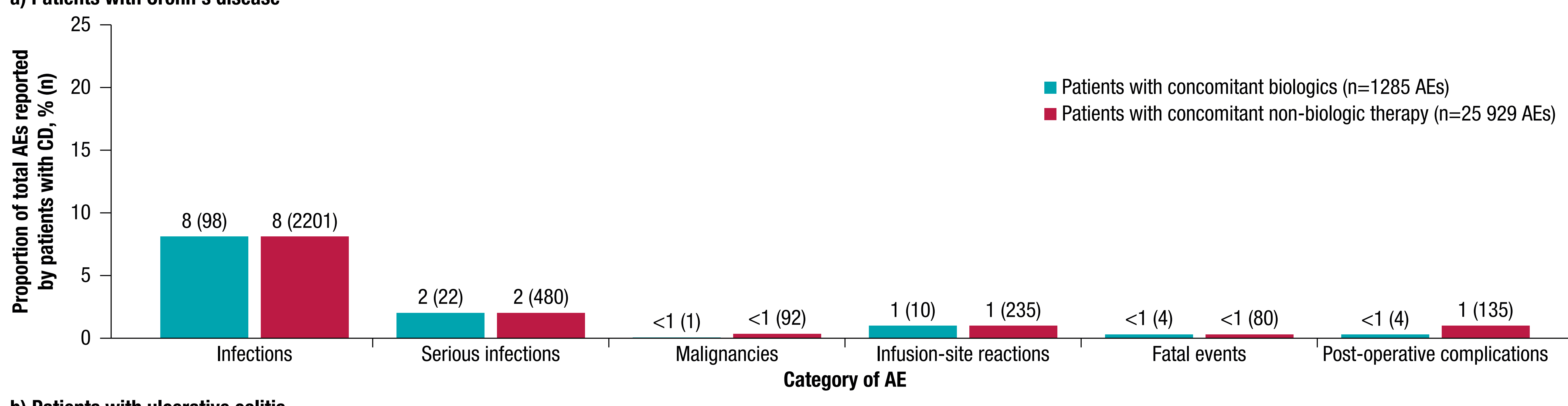

b) Patients with ulcerative colitis

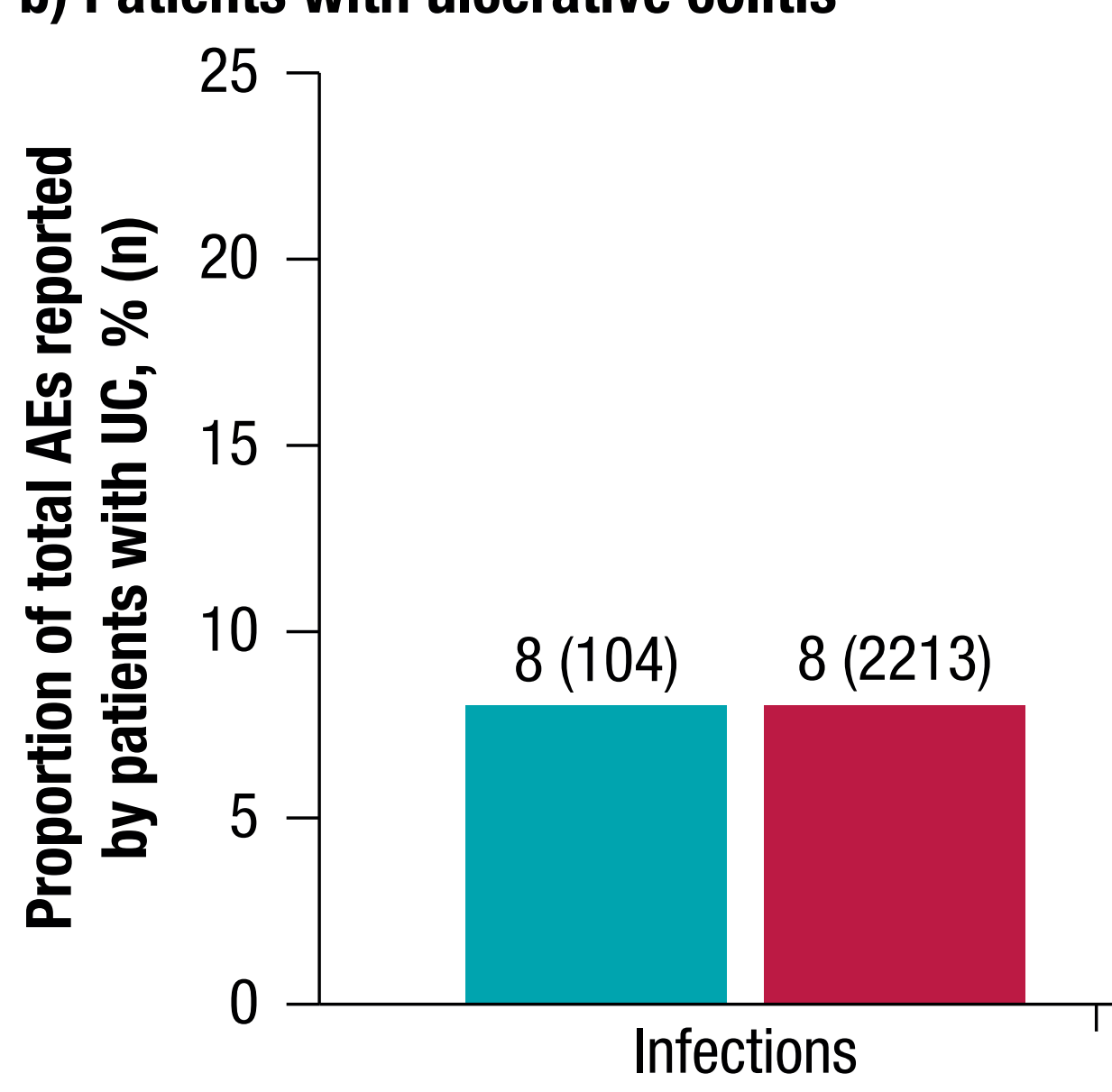

$2(21) \quad 1(324)$
Serious infections

$\begin{gathered}<1(1) \leq 1(84) \\ \text { Malignancies } \\ \text { Category of AE }\end{gathered}, \frac{<1(6)}{\text { Infusion-site reactions }}$

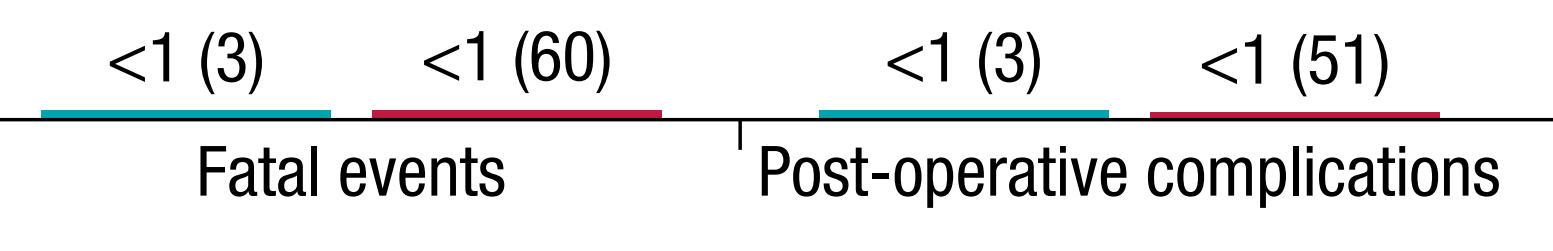

c) Patients with other indications

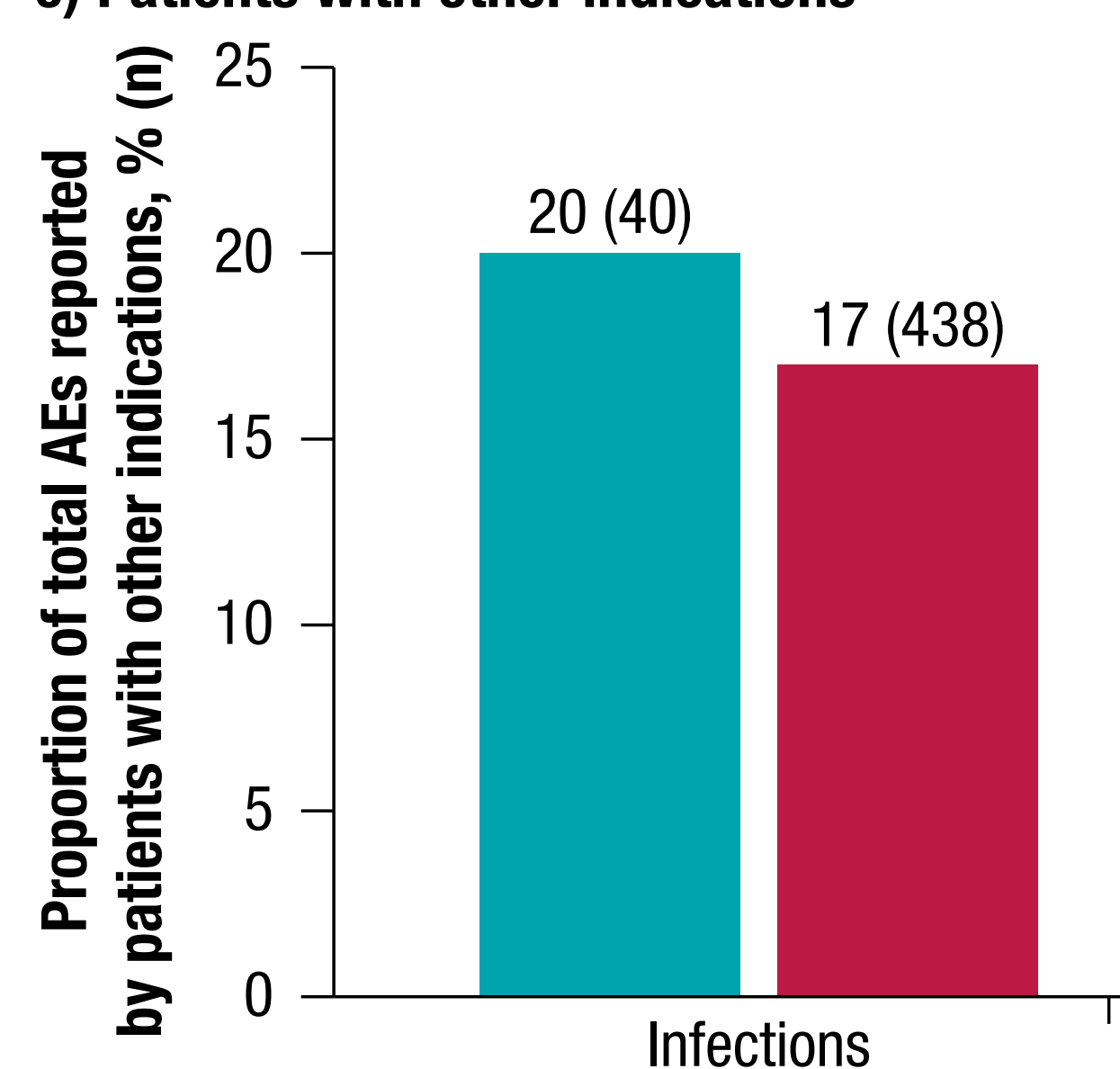

Patients with concomitant biologics $(\mathrm{n}=1363 \mathrm{AES})$ Patients with concomitant non-biologic therapy (n=26 272 AEs)

atients with concomitant biologics $(n=199$ AEs) with concomitant non biologic therapy ( $n=2654$ AEs)

\section{Including patients with unspectified inflammatory bowel disease, off-label use and unreported indica}

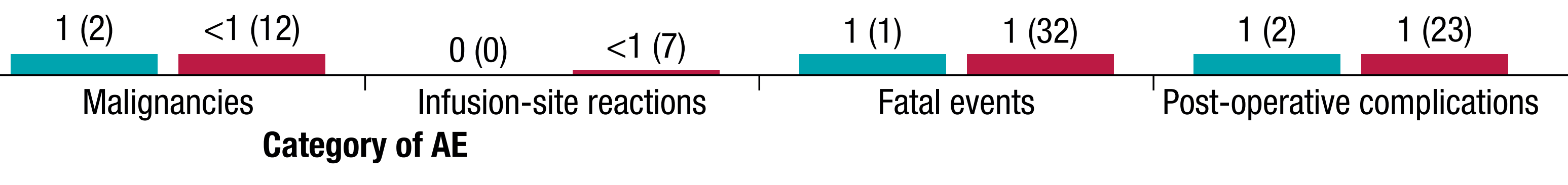

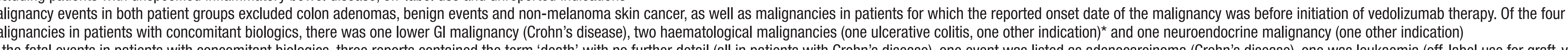
lost disease) and one patients with

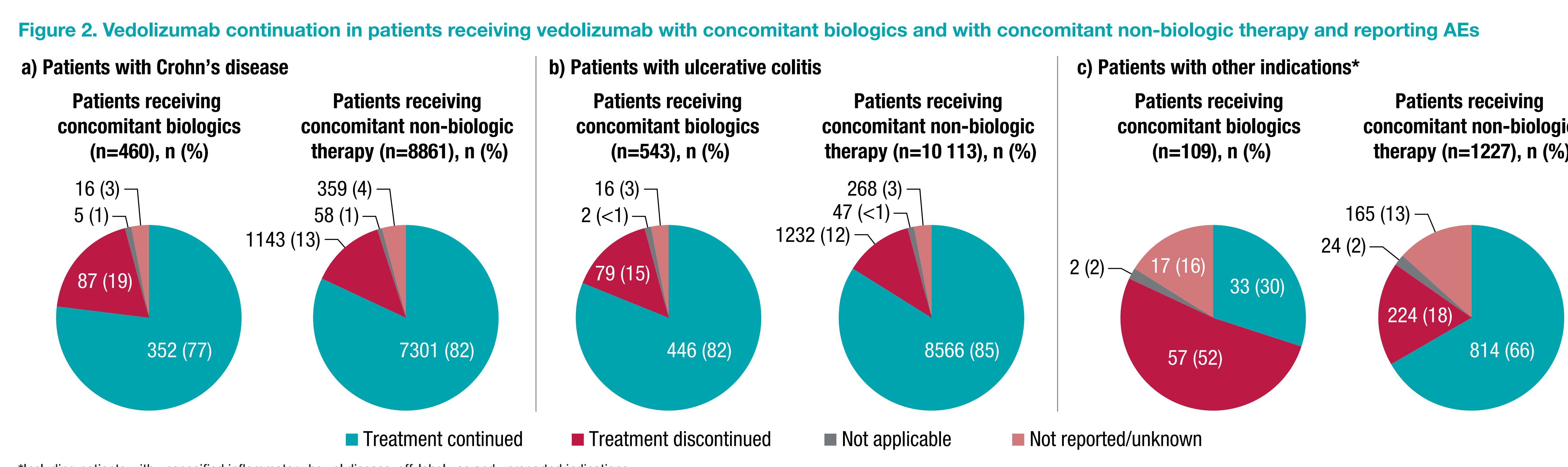

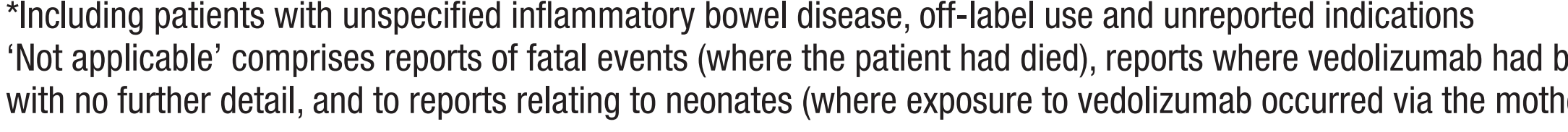

The proportion of AEs reported in each category of AE was similar for patients with
CD or UC. In patients receiving vedolizumab for other indications, the proportion of AEs patients with $\mathrm{CD}$ or $\mathrm{UC}$, and was slightly higher for patients receiving concomitant biologics compared with those receiving concomitant non-biologic therapy (Figure 1).

Continuation of vedolizumab treatment

Despite experiencing an $A E$, most patients with $\mathrm{CD}$ or UC receiving concomitan [

Similarly, 7301 patients with $\mathrm{CD}(82 \%)$ and 8566 patients with UC (85\%) receiving concomitant non-biologic therapy also continued treatment with vedolizumab, despite reporting an AE (Figure 2 ).

Table 1. Characteristics of patients reporting AEs while receiving vedolizumab with concomitant biologics and with concomitant non-biologic therapy

\begin{tabular}{|c|c|c|c|c|c|c|}
\hline \multirow[t]{2}{*}{ Characteristic, n (\%) } & \multicolumn{3}{|c|}{$\begin{array}{l}\text { Patients reporting AEs while receiving vedolizumab } \\
\text { with concomitant biologic treatment }\end{array}$} & \multicolumn{3}{|c|}{$\begin{array}{l}\text { Patients reporting AEs while receiving vedolizumab } \\
\text { with concomitant non-biologic treatment }\end{array}$} \\
\hline & $\begin{array}{l}\text { Crohn's disease } \\
n=460\end{array}$ & $\begin{array}{l}\text { Ulcerative colitis } \\
\mathrm{n}=543\end{array}$ & $\begin{array}{l}\text { Other indications* } \\
\mathrm{n}=109\end{array}$ & $\begin{array}{c}\text { Crohn's disease } \\
n=8861\end{array}$ & $\begin{array}{l}\text { Ulcerative colitis } \\
n=10113\end{array}$ & $\begin{array}{l}\text { Other indications* } \\
\mathrm{n}=1227\end{array}$ \\
\hline $\begin{array}{l}\text { Sex } \\
\text { Female } \\
\text { Male } \\
\text { Not reported }\end{array}$ & $\begin{array}{l}279(61) \\
178(39) \\
3(1)\end{array}$ & $\begin{array}{l}240(44) \\
301(55) \\
2(<1)\end{array}$ & $\begin{array}{l}69(63) \\
35(32) \\
5(5)\end{array}$ & $\begin{array}{l}5499(62) \\
3341(38) \\
21(<1)\end{array}$ & $\begin{array}{l}5130(51) \\
4954(49) \\
29(<1)\end{array}$ & $\begin{aligned} 723(59) \\
473(39) \\
31(3)\end{aligned}$ \\
\hline $\begin{array}{l}\text { Age, years } \\
<18 \text { years } \\
18-64 \text { years } \\
\geq 65 \text { years } \\
\text { Not reported }\end{array}$ & $\begin{array}{c}7(2) \\
406(88) \\
39(8) \\
8(2)\end{array}$ & $\begin{array}{c}6(1) \\
481(89) \\
48(9) \\
8(1)\end{array}$ & $\begin{array}{l}2(2) \\
75(69) \\
4(4) \\
28(26)\end{array}$ & $\begin{array}{l}118(1) \\
7089(80) \\
1484(17) \\
170(2)\end{array}$ & $\begin{array}{c}231(2) \\
8025(79) \\
1702(17) \\
155(2)\end{array}$ & $\begin{array}{l}28(2) \\
653(53) \\
195(16) \\
351(29)\end{array}$ \\
\hline $\begin{array}{l}\text { Concomitant biologics }{ }^{\ddagger} \\
\text { Concomitant anti-TNFa therapy } \\
\text { Other concomitant biologic therapy } \\
\text { Concomitant anti-TNFo and other biologics }\end{array}$ & $\begin{array}{l}339(74) \\
117(25) \\
4(1)\end{array}$ & $\begin{array}{l}520(96) \\
22(4) \\
1(<1)\end{array}$ & $\begin{array}{l}73(67) \\
34(31) \\
2(2)\end{array}$ & - & - & - \\
\hline $\begin{array}{l}\text { Other concomitant immunosuppressant } \\
\text { Yes } \\
\text { No }\end{array}$ & $\begin{array}{l}133(29) \\
327(71)\end{array}$ & $\begin{array}{l}167(31) \\
376(69)\end{array}$ & $\begin{array}{l}32(29) \\
77(71)\end{array}$ & $\begin{array}{l}2110(24) \\
6751(76)\end{array}$ & $\begin{array}{l}2399(24) \\
7714(76)\end{array}$ & $\begin{array}{l}276(22) \\
951(78)\end{array}$ \\
\hline $\begin{array}{l}\text { Concomitant corticosteroid } \\
\text { Yes } \\
\text { No }\end{array}$ & $\begin{array}{l}180(39) \\
280(61)\end{array}$ & $\begin{array}{l}261(48) \\
282(52)\end{array}$ & $\begin{array}{l}49(45) \\
60(55)\end{array}$ & $\begin{array}{l}3763(42) \\
5098(58)\end{array}$ & $\begin{array}{l}5697(56) \\
4416(44)\end{array}$ & $\begin{array}{l}432(35) \\
795(65)\end{array}$ \\
\hline
\end{tabular}

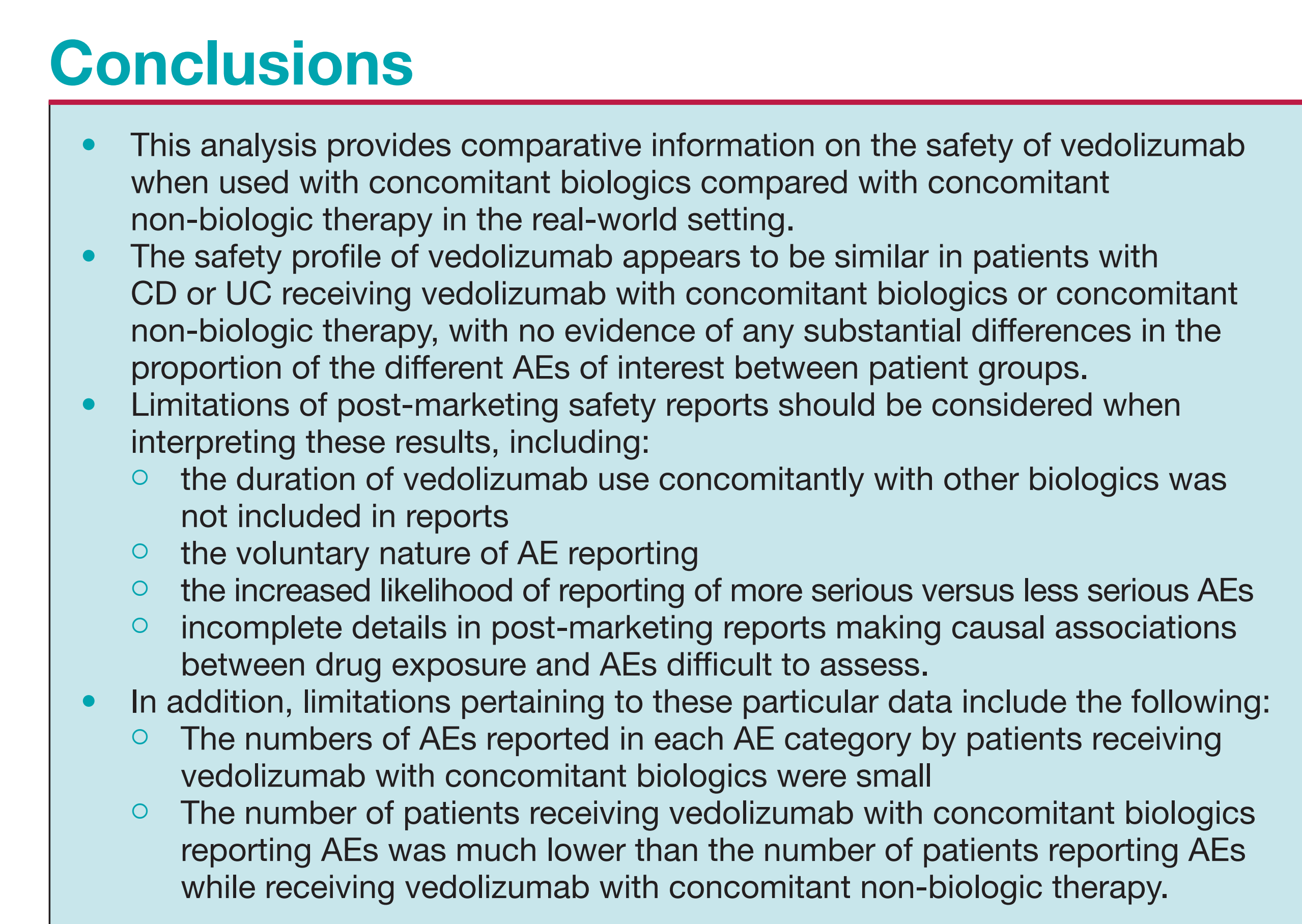

References

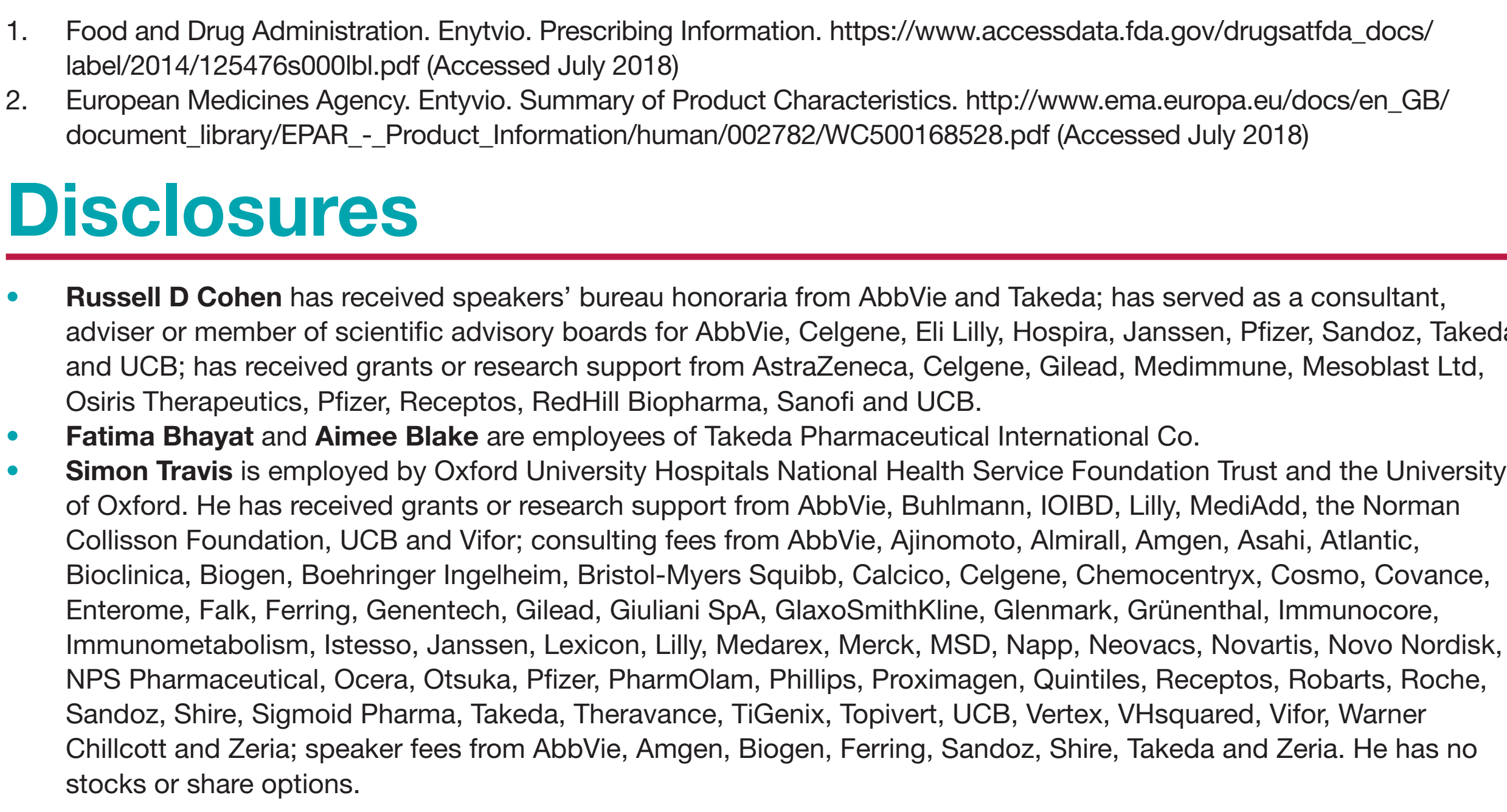

Acknowledgements

se and unreported indication

